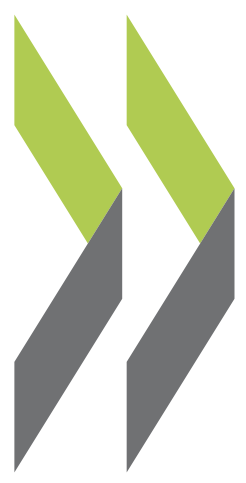

SIGMA Papers No. 29

\title{
Centralised \\ and Decentralised Public \\ Procurement
}

OECD 


\section{Unclassified}

Organisation de Coopération et de Développement Economiques

Organisation for Economic Co-operation and Development
CCNM/SIGMA/PUMA(2000)108

OLIS : 25-Oct-2000

Dist. : 26-Oct-2000

SIGMA -- A JOINT INITIATIVE OF THE OECD AND THE EUROPEAN UNION,

English text only PRINCIPALLY FINANCED BY THE EUROPEAN UNION'S PHARE PROGRAMME

\section{CENTRALISED AND DECENTRALISED PUBLIC PROCUREMENT}


THE SIGMA PROGRAMME

SIGMA - Support for Improvement in Governance and Management in Central and Eastern European Countries is a joint initiative of the OECD and the European Union. The initiative supports public administration reform efforts in thirteen countries in transition, and is principally financed by the European Union's Phare Programme.

The Organisation for Economic Co-operation and Development is an intergovernmental organisation of 30 democracies with advanced market economies. Its Centre for Co-operation with Non-Members channels the Organisation's advice and assistance over a wide range of economic issues to reforming countries in Central and Eastern Europe and the former Soviet Union. Phare provides grant financing to support its partner countries in Central and Eastern Europe to the stage where they are ready to assume the obligations of membership of the European Union.

Phare and SIGMA serve the same countries: Albania, Bosnia-Herzegovina, Bulgaria, the Czech Republic, Estonia, the former Yugoslav Republic of Macedonia, Hungary, Latvia, Lithuania, Poland, Romania, Slovakia and Slovenia.

Established in 1992, SIGMA works within the OECD's Public Management Directorate, which provides information and expert analysis on public management to policy-makers and facilitates contact and exchange of experience amongst public sector managers. SIGMA offers beneficiary countries access to a network of experienced public administrators, comparative information, and technical knowledge connected with the Public Management Directorate.

SIGMA aims to:

- assist beneficiary countries in their search for good governance to improve administrative efficiency and promote adherence of public sector staff to democratic values, ethics and respect of the rule of law;

- help build up indigenous capacities at the central governmental level to face the challenges of internationalisation and of European Union integration plans; and

- $\quad$ support initiatives of the European Union and other donors to assist beneficiary countries in public administration reform and contribute to co-ordination of donor activities.

Throughout its work, the initiative places a high priority on facilitating co-operation among governments. This practice includes providing logistical support to the formation of networks of public administration practitioners in Central and Eastern Europe, and between these practitioners and their counterparts in other democracies.

SIGMA works in five technical areas: Public Administration Development Strategies; Policy-Making, Co-ordination and Regulation; Budgeting and Resource Allocation; Public Service Management; and Audit and Financial Control. In addition, an Information Services Unit disseminates published and on-line materials on public management topics.

Copyright OECD, 2000

Applications for permission to reproduce or translate all or part of this material should be made to: Head of Publications Service, OECD, 2 rue André-Pascal, 75775 Paris Cedex 16, France.

Views expressed in this publication do not necessarily represent official views of the Commission, OECD Member countries, or the central and eastern European countries participating in the Programme. 


\section{FOREWORD}

Central and eastern European countries conduct public procurement on a highly decentralised basis, at the level of individual spending ministries, local authorities or other public bodies covered by the procurement law. However, in some cases, there may be advantages in mixing this approach with elements of centralisation, as is the case in many EU Member States. This paper reviews the experience of selected EU countries.

The establishment in many central and eastern European countries of public procurement offices that are not responsible for actual purchasing but set national policy, organise training, draft legislation, etc., represents a great change from the earlier central monopoly purchasing systems. The purchasing function itself has been decentralised to hundreds or sometimes thousands of procuring entities. Many countries in the region see the new procurement model as part of the process of democratisation and do not want to replicate earlier institutions and mistakes. They are trying to move rapidly from one system to another. This paper sheds light on the various issues to be considered in deciding how procurement systems in these countries might evolve in the future.

The target audience is primarily public procurement offices in Central and Eastern Europe, but the paper could also prove useful to other transition and developing countries that are in the process of modernising their procurement laws and systems.

Many authors have contributed to this paper, including the Annex which summarises procurement law and practices in place in several EU Member States. The contributors are listed here in alphabetical order: Peter Bennett (UK) (peter.bennett@hm-treasury.gov.uk), Peder Blomberg (Sweden) (peder.blomberg@hifab.se), Ingo Brinker (Germany)(bk2@stu.gleiss-law.com), Steen Bruun-Nielsen (Denmark) (sbn@indigo.ie), Glenn Fletcher (UK) (glennf@achilles.co.uk), Alain Gillette (France) (agillette@accompetes.fr), Unto Kariniemi (Finland) (unto.kariniemi@hansel.fi), (Velia Leone (Italy) (velia.leone@ berwinleighton.com), Franz Vos (Netherlands) (frans.vos@nic-int.nl), and Gösta Westring (Sweden) (gosta.westring@cederq.se). Cynthia Walker (cynthiawalker@attglobal.net) managed the SIGMA project.

For further information, please contact Piotr-Nils Gorecki, SIGMA Administrator for Public Procurement, at the address below.

All SIGMA Papers are available on SIGMA website or from the address below.

This paper is published on the responsibility of the Secretary-General of the OECD.

SIGMA-OECD, 2 rue André-Pascal, 75775 Paris, Cedex 16, France

Tel. (33.1) 45.24.79.00; Fax: (33.1) 45.24.13.00

e-mail: sigma.contact@oecd.org; http://www.oecd.org/puma/sigmaweb 


\section{EXECUTIVE SUMMARY}

A decentralised approach to public procurement in which contracting entities in state bodies covered by the relevant legislation are responsible for conducting procurement activities is widely accepted as the preferred solution to public purchasing policy. Such an approach contrasts with a centralised approach whereby one government organisation representing the collective needs of ministries and other state bodies carries out procurement functions. The rationale for relying on a decentralised approach is that by placing the procurement function closer to the needs of the final user, it is likely to be more economically efficient and better able to promote the development of the private sector, including small and medium-sized enterprises (SMEs).

But does the evidence support this view? Whilst a decentralised approach may promote the development of the private sector, does it also sacrifice the potential advantages of bulk buying and economies of scale? Do adjustments need to be made in transition countries to introduce elements of a centralised approach within a broadly decentralised model? And how can proper enforcement of procurement regulations be ensured in a decentralised model in which the centre may have insufficient information with which to monitor compliance of procurement transactions with the law and whether they are delivering value for money?

This paper reviews several different mechanisms for organising procurement operations on a centralised basis: national purchasing groups, regional and local procurement groups, joint ventures and partnerships, cross-border procurement agreements, specialised agencies concentrating on one or more fields of supplies or services, and framework contracts. Several EU Member States are already making use of mechanisms such as these, combining them with an overall approach based on decentralisation. The paper also considers the implications of the growth of e-commerce in the procurement field.

Arguments for and against such forms of centralised procurement are presented and discussed in depth.

The key arguments that are usually put forward in support of centralised procurement are:

- Significant reductions in prices of goods and services;

- Better services at lower cost;

- Increased purchasing power for the centralised agency;

- Need for technical standardisation (e.g., within the area of IT systems and software applications) and the setting and inclusion of environmental standards for government procurement;

- Non-cost benefits including greater attention to contract management and better problem resolution (e.g., faulty items, below specification services, after sale maintenance);

- Lower costs of training staff because they are fewer in number and centrally located;

- Easier performance management of staff; and

- Encouragement of good transparency provisions such as efficient recording and reporting of procurement contracts and transactions, effective management controls, clearer audit trail. 
The key arguments in support of decentralised procurement are:

- Reduced incentives for corruption via large-scale protectionism or favouritism;

- A closer matching of goods and services delivered to the detailed requirements of end users;

- Reduced scope for mistakes affecting large volume purchases that result in unnecessary over-spending;

- Less bureaucracy because of shorter time frames and fewer forms for both purchasers and suppliers;

- Greater possibilities for SME's to compete successfully for contracts;

- Opportunities for local purchasers to obtain lower prices for locally manufactured goods; and

- More scope for employees to take individual responsibility and develop a "service" mentality.

The general conclusion of the paper is that there are a number of possible procurement strategies available to public agencies in EU Member States and central and eastern European countries. The choice of strategy depends on the culture and circumstances of the country concerned, including the level of economic and market development. The centralisation vs. decentralisation debate is not an issue of black vs. white. A system that mixes elements of decentralisation and centralisation is likely to work well in many countries. Adaptation over the long-term to the requirements of e-commerce need also to be considered.

Questions are frequently asked about the laws and practices of EU Member States in this area. Attached to this paper is an Annex prepared by experts from seven selected countries ${ }^{1}$, summarising the main features of their national public procurement systems, with special emphasis on decentralisation/centralisation issues.

1. Denmark, Finland, Germany, Italy, the Netherlands, Sweden, and the United Kingdom. 


\section{INTRODUCTION}

This paper examines whether or not, and to what extent, it is desirable for countries in Central and Eastern Europe to reverse the apparently inexorable trend away from the planning systems within the former command economies towards implementing a largely decentralised approach to procuring (non-military) goods and services. This could take one of several forms: for example, establishing a centralised purchasing agency, groups of purchasing entities, or firms selling specialised supplies or services, such as computers or computer services, or making greater use of framework contracts.

For countries that are candidates for European Union membership, it is important to note that the EC Public Procurement Directives ${ }^{2}$ are silent on this matter. It is regarded as an issue of subsidiarity (i.e. national decision-making) as to what form of administrative arrangements are established in a Member State, provided that country meets its Treaty obligations concerning the openness and transparency of the procurement process, and to promote competition within the Community. However, in practice, many EU Member States already mix elements of centralisation and decentralisation in their procurement systems.

This paper: a) reviews the classic arguments for and against centralisation of procurement operations; b) examines various "modern" models of centralised procurement that might be included within an overall approach that remains broadly decentralised; and c) considers the possible long-term impact of eprocurement. The Annex reviews the experience of several EU Member States in this field.

\section{Arguments for Centralisation of Procurement}

The main argument in favour of centralised procurement lies in the potential economies of scale. Volume purchases makes it possible to obtain significant reductions in the price of goods or to receive better services at lower costs. This is confirmed by the fact that most procurement agencies/associations report growth in their sales even after they lose their earlier monopoly status and despite aggressive marketing by their competitors.

2. Council Directive 92/50/EEC of 18 June 1992 relating to the co-ordination of procedures for the award of public service contracts; Council Directive 93/36/EEC of 14 June 1993 co-ordinating procedures for the award of public supply contracts; Council Directive 93/37/EEC of 14 June 1993 concerning the coordination of procedures for the award of public works contracts; Council Directive 93/38/EEC of 14 June 1993 co-ordinating the procurement procedures of entities operating in the water, energy, transport and telecommunications sectors; and the two "Remedies Directives": Council Directive 89/665/EEC of 21 December 1989 on the co-ordination of laws, regulations and administrative provisions relating to the application of review procedures to the award of public supply and public works contracts; and Council Directive 92/13/EEC of 25 February 1992 co-ordinating the laws, regulations and administrative provisions relating to the application of Community rules on the procurement procedures of entities operating in the water, energy, transport and telecommunications sectors. Directive 89/665 applies in relation to public procurement covered by the Supplies, Works and Services Directives. Directive 92/13 applies to procurement by entities operating in the utilities sector under the Utilities Directive. For further information, please refer to full texts of the Directives available on the European Union's Eur-Lex website at http://europa.eu.int/eur-lex/index.html. Specifically, use the "Legislation in Force" search function at http://europa.eu.int/eur-lex/en/search_lif_simple.html and enter the year and number of each Directive. 
A large producer should be able to achieve greater savings that can be passed on in the form of reduced prices if he has a single large contract with a centralised procurement body. Such a contract gives the producer access to a wider market with fewer fluctuations in his costs as a large number of orders can be processed simultaneously. Production lines and staff can be organised more efficiently. The management of sales is simplified for the producer who in effect sub-contracts the sales side to the procurement agency.

In theory, after obtaining a large contract with a centralised procurement agency, an entrepreneur should be able to increase his profits, invest, and/or lower his prices to become more competitive. This benefits the centralised procurement agency as lower prices are offered. However, this argument is losing some weight with the increase in industrial automation which makes it possible to produce customised products at a similar cost to mass produced products. For example, a hospital can order 10 uniforms made of a certain colour and design for the same cost as would earlier have required an order of 1000 because the order is given and executed through a computerised production system.

The influence of lower prices and higher demand is not, however, simply the result of bulk purchase. Although marginal costs of production and the risk to the supplier can both be reduced with a contract for a large quantity of goods and/or services, there are other economic benefits. The increased purchasing power of the agency allows the supply base to be streamlined and overhead costs to be reduced. It also allows the proactive purchaser to seek changes in the supplier's organisation and production methods, further reducing costs.

Centralised efforts are often justified by the need to establish technical standards for information technology systems and computer software applications within the government sector and, similarly, to set environmental standards for the inclusion in technical specifications and contracts with suppliers. It is less easy to achieve these objectives if the government's purchasing system is highly fragmented, particularly in the absence of a public procurement office with sufficient formal and informal powers.

Potential non-cost benefits which support centralised purchasing groups include, as already mentioned, better service to the customer resulting from a more expert and responsive staff. Greater attention can be paid to contract management and problem resolution (e.g., faulty items, below specification services, poor after sale maintenance, etc.) which add value for the client and which are easier to deliver in a more centralised system.

Human resources should also be easier to manage in a centralised system. Training of staff can often be more easily undertaken as many staff members are centrally located. Performance management of staff can be handled through a common system. Fewer people need to be trained as there are fewer agencies requiring skilled and experienced procurement specialists. The increased professionalism that specialist purchasers can bring to centralised procurement will enhance the economic benefits already referred to and should reduce the chances of error undermining these effects. A dedicated procurement team is more likely to be able to deliver increased benefits year after year which even during sustained periods of budget stringency.

Finally, centralised purchasing systems encourage the spread of the good transparency provisions such as proper recording and reporting of transactions, effective management controls, and an audit trail open to public scrutiny. Purchases can more easily be checked for evidence of financial mismanagement and corruption. In addition, the employees of a single agency can more easily be trained and encouraged to use efficient control and reporting procedures. Lines of responsibility are more easily established and sound financial practices more easily maintained. 


\section{Arguments against Centralisation of Procurement}

Centralised procurement is sometimes seen as encouraging corruption as it can involve large-scale protectionism or favouritism. In such cases, competition is not encouraged and lower prices are not obtained. On the other hand, as noted above, it is easier in a centralised procurement agency for senior management to stress the benefits of transparency and openness and to introduce the necessary control and reporting procedures. Often, corruption may be more prevalent and easier to disguise in smaller procurement operations since corrupt payments are relatively small and do not need to be shared out among many employees.

Another argument against centralised procurement is that it can lead to purchases of unsuitable goods and services as the specific, detailed requirements of all end-users cannot be taken into account. Professional purchasers must always be wary of the distance between their own assessment of their needs and what can be delivered on a central basis. In practice, only certain items will be suitable for central procurement, and that list will vary over time and with technical and commercial developments. The mistakes made by centralised procurement systems in selecting unsuitable goods and services may in fact affect a large volume of purchases and result in substantial overspending. Users are not likely to support arrangements that do not meet their quality needs (one size does not fit all) or that are demonstrably more expensive than a product or service which can be purchased locally at a lower price. There will always be inefficiencies in the delivery of goods and services in both centralised and decentralised procurement. What is important is that care be taken to ensure that these inefficiencies are outweighed by the benefits.

In any discussion of centralised purchasing in the context of transition economies, the potential impact on the development of local markets, including small and medium-sized enterprises (SMEs), must not be forgotten. Even within a decentralised procurement regime there is no guarantee of procurement contracts for smaller companies. The goal of encouraging SMEs, while sometimes one of the non-commercial objectives of a centralised buying organisation, usually do not produce the anticipated benefits for the development of local markets. There is no doubt that the larger the contract, the less likely it is that a smaller company will offer the best value for money. Public procurement contracts are often too big for smaller firms, even without aggregation or by entering into consortia with other firms. Moreover, an SME that is consistently successful in obtaining contracts from one centralised purchasing agency may place too much dependence on work with that agency and, at the end of the contract, the company may find it difficult to identify new sources of business.

It should be noted, however, that while some observers claim that centralised procurement agencies can be detrimental to SMEs, others point out that they sometimes provide unexpected and positive business opportunities. A policy of encouraging efficient procurement by the government needs to be balanced with policies to promote the growth of the market economy, including the development of a healthy SME sector.

Finally, there is a risk, within a centralised system, that the needs of the user are not fully satisfied since such systems inevitably involve some rationalisation and homogenisation of demand. Where users are held to account for the effectiveness of the public services they provide, they may be reluctant to entrust procurement to "distant" officials, who do not necessarily understand their needs or have an interest in issues concerning the customers' accountability. 


\title{
Modern Approaches to Centralised Procurement
}

a)

\author{
National Purchasing Groups
}

There is no standard model for the organisation of purchasing agencies in the European Union. Many EU Member States started out with centralised purchasing offices or groups of offices managed and owned by the state. A central purchasing agency makes bulk purchases directly from suppliers, and government agencies and departments are required to buy through the agency. This is the so-called "monopoly" method, which is infrequently used nowadays.

Over the past 20 years, the purchasing agency's functions have been decentralised in most countries. Many agencies are still wholly or partially owned by the state but have changed their legal status (e.g., have become a private company owned by the government) and been given a greater degree of financial and managerial autonomy. They may not be expected to make a profit but must be financially selfsufficient and (in some countries) may offer services on a contracting-out basis or sell to private entities. Government entities are frequently "untied", i.e., are free to make their purchases from organisations and companies other than the centralised entity.

Such purchasing agencies use methods similar to the private sector to ensure that they are run profitably and efficiently. Their employees' remuneration tends to diverge from that in the public service, even when the employee is seconded from the public service, and is sometimes enhanced by performance related pay schemes. In some countries, the degree of state ownership has been reduced or even eliminated when the agencies concerned have been privatised.

The attractiveness of such centralised purchasing agencies in the EU has decreased with the increasing commercial sophistication of user ministries and the increased importance of procurement for the achievement of government policy objectives. Remaining national agencies are concentrating on areas where they can delivery value for money.

\section{b) Regional and Local Procurement Groups}

In many countries, arrangements have developed for pooling the purchasing arrangements of groups of government offices, public bodies of various kinds (e.g., universities) or local authorities at the regional level. In certain cases, for example, several local authorities have formed consortia or joint ventures in order to purchase common services such as water, waste disposal and school meals. They may decide to purchase directly from another municipality or regional authority, or from the private market. In such cases, prices can often be negotiated that are significantly lower than if the organisations concerned make purchases individually.

Such centralised procurement groups often do not have separate legal personality but join together ad hoc and use framework contracts (see below) under which the specifications of goods and services and prices are agreed for a certain period of time. Under such arrangements, there is usually no obligation for users to use the framework contract; they are free to purchase from another source if they find a better offer.

A framework agreement is an agreement where the prices for each good/service to be supplied are set but the quantities to be purchased are not specified. Indeed, there may well be no obligation whatsoever to buy anything whatsoever from the seller. A framework agreement is a way of locking in prices on items when 
quantities cannot be set at the time of signing. Framework agreements are in common use both for the purchase of goods and for the use of services. Where, for example, a project needs further specification as to exactly how many consultants will be used and over what time period, a framework contract may be ideal. Framework supply contracts are often more effective than unwieldy competitive bidding procedures and will eliminate the work of preparing many bids for the same goods/services.

Earlier, framework contracts were not allowed by the European Commission on the principle that they discouraged competition. Centralised procurement officials have long asked for a relaxation of these prohibitions. They stress the impractical aspects of some European regulations (e.g., long lead times for competitive tendering procedures on items involving rapid price and/or technology changes). The European Commission, however, has indicated that it may authorise wider use of framework agreements so that procuring officers can take advantage of price reductions and technological developments on a more flexible basis.

\section{d) Cross-Border Procurement}

Although the "international" agency is very much the exception, some countries are extending the operations of their national procurement entities beyond their own frontiers. This is true, for example, of Germany's GTZ, the Netherlands' NIC, and the UK's Crown Agents and subsidiaries. All three organisations combine centralised purchasing with technical co-operation and the provision of services for their own governments, other countries, or international organisations. These organisations also offer technical assistance in procurement to the private sector (e.g., price checks on imports, independent quality inspection prior to shipment).

In practice, there has been little international co-operation among national procurement entities. Suppliers of equipment, furniture and current items, which form the bulk of procurement agencies' activities, seldom seek business outside their borders. Language and culture remain strong barriers. Another drawback in many cases is the geographic remoteness of the supplier from the end user.

\section{e) Specialised Agencies}

Procurement is an area where the practical benefits (in terms of improved value for money) are easily demonstrable and where specialised agencies may therefore have a strong advantage. A centralised procurement agency specialising in the provision of certain goods or services (e.g., medical equipment or drugs) may be able to offer lower prices and a higher quality of service to its clients than can smaller entities. Such agencies are also in a good position to educate users and suppliers and ensure the application of best practice. Providers of computer services, for example, will soon lose clients if insufficient attention is given to the development of market information, product quality, servicing capacity and building a longterm client relationship.

\section{The Impact of Electronic Procurement}

The development of e-commerce will have considerable effects on the way that public procurement is organised. The European Commission and the World Trade Organisation have already recognised this.

There will be an increased choice for the client. The availability of competing electronic catalogues on the Internet will allow clients to compare prices and have access to economies of scale without the need for any intermediary agency or centralised purchasing arrangement. 
Electronic procurement should yield substantial efficiency gains for purchasing agencies. Staff procurement expertise can be concentrated on establishing commercial arrangements rather than operating inefficient contract management and service delivery systems. Many agencies are already offering easyto-use catalogue systems (e.g., covering computer supplies). Agencies will be well placed to make purchasing contracts with suppliers (usually framework type arrangements) on the basis of the more assured demand they can obtain.

In the past, market prices were often set with reference to those obtained by procurement agencies. Sellers with price catalogues sometimes saved taxpayers money; without catalogue sales, prices might be higher. The volume of centralised procurement must be high enough to exert such economic pressure. However, this is another area that may be affected by the development of e-commerce.

So far decisions regarding centralised procurement have been based more on theory and the pragmatic verdict of the marketplace than on economic analyses, but e-commerce may change this soon. Public procurement has definitely entered the computer age. Centralised procurement agencies have set up computer systems enabling them to be in direct, individual contact with suppliers and customers. The European Commission is no longer mailing the public procurement supplement to the Official Journal of the European Communities, as it can now be consulted on the Internet. These trends foreshadow the eventual development of totally electronic markets in which catalogues, standards, filing and analysis of bids, contracts, product and supplier selection, orders, delivery schedules and payments will all be available on the Internet.

\section{Conclusion}

A consensus has emerged in recent years in favour of the liberalisation and privatisation of public procurement. Procurement agencies - even most non-defence government buyers and independent legal entities -- now have to compete with the private sector. In most cases, buyers -- sometimes operating together through partnerships or consortia -- can make transactions with any seller and are no longer required to deal exclusively with one supplier.

Central and eastern European countries and EU Member States started from different positions. In the EU countries, there is a long tradition of centralised procurement followed by a gradual liberalisation of these procedures over a fairly extended period. The strengthening of financial control and regulation of procurement procedures, as well as annual audits of private sector suppliers have accompanied this process. Arrangements for the training and staff development of procurement personnel have also improved in recent years as the financial importance to individual countries of good procurement practices has come to be realised. The EU Member States benefit from having a developed market sector and many private enterprises and suppliers who can deliver goods and services as needed.

Not all these factors are present in central and eastern European countries. They are being pressured to adapt their systems over a very short period of time to systems that in the EU have been developed over a much longer period of time. Under the Soviet regime, the systems in Central and Eastern Europe were entirely centralised. Now most are being encouraged to adopt severely decentralised systems and to train vast numbers of people accordingly.

It is important to get the preconditions right so that a functioning procurement system can actually be achieved. A number of possible procurement strategies -- centralised or decentralised -- are available to purchasers in both EU Member States and central and eastern European countries. The mix of strategies must be determined on the basis of balance of advantage for each commodity/organisational structure and should be kept under review. 


\section{ANNEX: SUMMARY OF PROCUREMENT LAW AND PRACTICES IN EU MEMBER STATES}

\section{Denmark}

Denmark does not have a special agency with a mandate to purchase on behalf of other government authorities. However, there is a system for central use and co-ordination of framework agreements. When the Government Procurement Agency was established in 1976 under the remit of the Ministry of Finance, it took up framework contracts as a means for furnishing government entities with goods and services.

The contracts are not subject to specific legislation. They are contracts running for a specified period containing specified prices and other conditions but without specific amounts of goods or services to be delivered. The Government Procurement Agency awarded the contracts by means of tenders in accordance with the EC Directives. Any interested entity could thereafter draw on the contracts without new tendering procedures. The framework scheme was never mandatory for government entities.

In 1982, a circular issued by Ministry of Finance recommended entities to use framework contracts issued by the Government Procurement Agency. This recommendation was only issued after consulting the European Commission, as the Directives on Public Procurement at that time did not address the issue. The Commission accepted the practice as not being contrary to the Directives.

During negotiations about the Utilities Directive, a UK and Danish initiative led to framework contracts and their use being included in the Directive. Although the relevant provision is still in the latest version of the Utilities Directive, it has not found its way into later versions of the Supplies or Services Directives. However, it is apparently generally accepted that framework contracts may be used as long as these do not discourage competition or lead to distortion of the equal treatment of suppliers.

As the Utilities Directive states that framework contracts may not be misused, the Danish Government consulted the Commission when in 1995 the Government Procurement Agency in 1995 was merged with a similar municipal entity so as to cater for both governmental and municipal entities. This new entity, the Procurement Service for State and Municipalities (SKI), is a private company owned by the Ministry of Finance and the National Organisation of Municipalities. The Commission did not object to this further centralisation, as the merger was not found to threaten competition or free access to the public market.

SKI is currently administering 85 framework contracts involving approximately 250 suppliers of goods and services. The contracts cover 16 main categories of goods and services ${ }^{3}$ and roughly 5600 entities subscribe to the services of SKI. The annual turnover on the framework contracts is around 400 billion euros.

\section{FINLAND}

Current policy and legislation tend to promote centralised procedures. Indeed, centralised procurement by means of framework contracts and collaborative procurement entities (CPE) has been common in Finland for decades. Most local government procurement activities consist of relatively small purchases that are under the EC Directives threshold values. Present practice encourages procurement entities to co-operate

3. For example cars and spare parts, office equipment, IT and communication, furniture and stationery. In the field of services the contracts mainly concern various travel and insurance services. 
at all levels of their procurement activities. The aim is to attain the best possible prices and other conditions and thereby achieve considerable savings.

Legislation also provides that individual procurement entities are allowed to procure products and services without competitive tendering through the $\mathrm{CPE}$, which follows competitive tendering procedures established in the EC Directives and/or national legislation. CPEs are usually established by local government entities on a voluntary basis to take care of their procurement needs in a joint manner. They are usually joint ventures without a separate legal personality. The aim of this legislation is to avoid unnecessary multiple competitive tendering and enable streamlining of procurement procedures.

The Government Purchasing Centre (the Centre) was established as a CPE in 1941. It acted as a public authority until 1995 when a change in the legislation ${ }^{4}$ allowed it to be incorporated as a limited liability company called Trading House Hansel Ltd (Hansel). Hansel and its predecessor are exceptions among the CPEs; they were established by law. Hansel awards contracts by means of tenders in accordance with the EC Directives.

From the 1960s it was compulsory for the state government procurement entities, but not local authorities, to procure via the Centre. Since the establishment of Hansel, public sector customers have had the right to decide whether or not to use its services. State government entities are allowed to order directly from Hansel without new tendering procedures.

From the beginning of 1990s there has been a strong trend towards decentralising public administration, including public procurement, and an emphasis on management by results. In 1998, a committee was established to evaluate the administration of state procurement ${ }^{5}$. In this context, public procurement was interpreted to mean not only competitive tendering procedures but rather the complete procurement cycle and related information flows. The committee's conclusion was that uncontrolled decentralisation had led to increased inefficiency in public procurement. It recommended that, by taking advantage of modern management models (e.g., concentration on core businesses) and new technologies (e.g., e-commerce), it should be possible to combine the benefits of both centralised and decentralised procurement systems in a new approach: the shared model.

The committee estimated that the potential saving from adopting the new approach would be more than 2 billion FIM (336.4 million euros) by the year 2002. Two-thirds of the savings were anticipated to come from the reduction of procurement processing costs and re-organising procurement procedures. Ecommerce was seen one of the major tools for realising this savings potential. One-third of the savings were expected to come from the lowering of purchase prices as a result of greater use of competitive tendering and economies of scale.

Finland aims to conduct 30 per cent of its public procurement through e-commerce by the year 2003. Ecommerce is also part of Finland's National Information Society Program and its Modern Government vision ${ }^{6}$.

4. Act of Incorporating the Government Purchasing Centre to a Limited Company (1508/94).

5. Ministry of Finance's Budget Department (1998), Committee of the State Public Procurement, Helsinki, ISBN 951-804-061-3, 29 pages. (Committee Reports, ISSN 0788-6322; 23/1998.)

6. Finnish National Fund for Research and Development (1998), Quality of Life, Knowledge and Competitiveness: Premises and Objectives for Strategic Development of the Finnish Information Society, Helsinki, ISBN 951-563-357-5, ISSN 0785-8388. 


\section{GERMANY}

In Germany, procurement has traditionally been carried out on a decentralised basis. Due to recent financial constraints, however, some public institutions, particularly municipalities, have considered alternative ways of procuring goods and services in order to achieve savings. Some municipalities, e.g., in Lower Saxony, have established centralised procurement bodies which can take various forms, e.g., limited liability companies (Gesellschaft mit beschränkter Haftung), co-operatives, and partnerships.

The establishment of centralised procurement bodies has been challenged under the German Act Against Restraints of Competition (Gesetz gegen Wettbewerbsbeschänkungen, GWB). Such challenges were based on the argument that the establishment of centralised procurement bodies is a restraint on competition under the terms of the anti-cartel provisions laid down in Section 1 of the GWB. Whilst the contracting entities argued that such provision only applies to agreements between private companies, some German courts have decided that procuring entities, whether at the municipal level or in the utilities sector, act like private companies and therefore fall within the scope of Section 1 of the GWB. A decision of the German Federal Supreme Court (Bundesgerichtshof) is still outstanding.

\section{ITALY}

Italy's domestic legislation in the public procurement field dates from the 1920's and is still in force, albeit much amended by subsequent legislation. It regulates central government procurement in general and provides for public tender procedures for choosing contractors similar to the provisions laid down by the Community Directives (Royal Decrees 2440/1923 and 827/1924). This legislation establishes general rules that are formally binding only for the central government, but that are also used as a reference by regional and local governments.

There is also a great deal of specific legislation relating to law and order in the public procurement sector. Due to concerns about the involvement of organised crime in public procurement contracts, there is legislation designed to prevent government contracts from being awarded to individuals who belong to, or are suspected of belonging to Mafia organisations.

Article 117 of the Italian Constitution gives regional governments legislative power parallel to that of the central government in specific fields such as town planning, health and public works. This legislative power must be exercised within the limits laid down by central government legislation and must not conflict with the national interest or the interests of other regions. In the public works sector, the general legislation applicable to all contract procedures, whether for amounts larger or smaller than the Community threshold, lays down that the regions and the bodies financed by them, as well as the Autonomous Provinces of Trento and Bolzano, are only required to comply with the Directives. They may adopt implementing legislation that is different from national legislation. Regions with special status have adopted their own autonomous regulations for public procurement procedures.

Following a major reform giving greater autonomy to local government organisations (communes and provinces) launched in 1990 and still under way, local authorities can now adopt their own specific regulations in the public procurement field. Specific legislation is also being passed in the special sectors (water, energy, telecommunications and transport) currently undergoing a complex process of privatisation, since in Italy these services are in fact managed by publicly owned joint stock companies. 


\section{THE NETHERLANDS}

The Netherlands' Rijks Inkoop Bureau (RIB) was established in 1921. The objective of this centralised government procurement office was efficient spending of government money. Initially, the responsibilities of the RIB covered only a limited number of goods such as office and school supplies and its clients were restricted to government entities. In 1949, 1967 and 1980, however, amendments to the law were issued increasing the number and type of goods covered by the RIB as well as expanding the range of its clients.

In the 1980s, discussions started in the Netherlands about the strengthening of the market economy and associated economic liberalisation, deregulation, privatisation, and the changing role of government in the economy. Positive factors such as more far-reaching international co-operation and negative factors such as the bankruptcy of centrally planned economies reinforced this trend. The ensuing growth in international competition was considered important not only for the private sector but also -- and increasingly -- for parts of the public sector.

As a result of this discussion, the RIB was privatised on 1 January $1990^{7}$ and renamed Nederlands Inkoopcentrum (NIC). On the same day, the regulation that required all governmental organisations to use the services of the RIB/NIC was abolished. The NIC's employees were no longer classified as civil servants, and the newly established organisation had to act as a private company. Potential clients had to be found in both the public and private sectors.

In Parliament it was, however, decided that the shares of NIC would remain in the hands of the government for an unspecified transition period. It is now expected that full privatisation will occur in the year 2000 .

Immediately after the regulation for compulsory utilisation of the RIB was abolished in 1990, NIC started charging fees for services performed. Although the NIC was successful in negotiating framework agreements with some large governmental entities, it encountered some losses in the first years of its operation. It tried to cope by reorganisation and other improvements, as well as by extending its services. The public sector remained its main focus of interest due to its knowledge of public spending programmes, expertise on special commodities and old established relations with state bodies.

Since 1995, NIC has been making a profit and now approximately four-fifths of public sector spending is contracted (on a voluntary basis) by the NIC for (non-military) commodities, cleaning, and security, copying, and similar services. The remaining procurement activities are conducted directly by the ministries concerned or though other procurement agencies.

The price/quality ratio of the NIC's services appears to be relatively attractive and, recently, even larger private sector companies have started to utilise NIC's services for their non-strategic commodities.

\section{SWEDEN}

Sweden does not have a special agency with a mandate to purchase on behalf of other government authorities. However, there is a system for central use and co-ordination of framework agreements with call-off arrangements for contracting entities within the government sector.

Under a framework agreement, prices and all other relevant contractual terms except quantities are agreed in advance between the supplier and contracting authority. There are normally no firm commitments from

7. Staatsblad 199025 Wet N.V. Nederlands Inkoopcentrum (NIC). Law No. 25 dated 28 December 1989. 
the purchaser to use the agreement, while the supplier is bound to deliver in the case of a call-off order by a contracting entity.

The co-ordinating body for the administration of framework agreements is the Legal, Financial and Administrative Services Agency (Kammarkollegiet). Its roles are (1) to ensure that framework agreements are used for the supplies that contracting authorities frequently need (e.g., office equipment, computers, paper), and (2) to monitor the use of framework agreements by compilation of statistics and other measures.

A Regulation ${ }^{8}$ of 25 June 1998 provides the guiding principles under which state authorities co-ordinate their procurement activities. The Regulation assigns the right to conclude framework agreements to ten state authorities within their special areas of responsibility (e.g., Statskontoret on computers and software), but all framework agreements of state authorities must be registered centrally and accessible from the database maintained by Kammarkollegiet. The Regulation only covers entities in the state sector falling under the jurisdiction of the government and not regional authorities and municipalities. However, regional and local authorities have systems for co-ordination and co-operation in many areas of procurement, including the frequent use of framework agreements.

The use of framework agreements is widespread and forms an important feature of the Swedish public procurement system. More than 300 framework agreements have been signed with over 300 suppliers for approximately 100 product groups. Total annual procurement related to framework agreements exceeds 700 million euros in value and represents around 5 per cent of total procurement activities by the state sector. The law requires that opportunities for small and medium-sized enterprises to participate in framework agreements must be taken into account, e.g., by allowing for sub-contracting and setting qualification criteria at an appropriate level.

\section{UNITED KINGDOM}

In the United Kingdom, the main emphasis of the government's policy on public procurement, which is set out in procurement guidelines, is to obtain value for money, (defined as the optimum combination of quality and whole life cost) usually through competition. For local authorities, this is supplemented by a law passed in the 1980s, which prohibits them from taking account of non-commercial considerations when awarding contracts. In the 1990s, the UK gave effect to obligations under the European Community and WTO Government Procurement Agreement (GPA) through four sets of Regulations, or Statutory Instruments $(\mathrm{SIs})^{9}$. These cover rules for the award of works, supplies and services contracts by public sector bodies and also by utilities. Each of the Regulations contains compliance provisions.

The approach to procurement in the UK is best described as decentralised. Policy and practice are the responsibility of the Treasury's Procurement Group, which gives guidance and central direction to government departments (i.e. ministries). However, each department is responsible for and accountable for getting value for money from their expenditure on goods and services. Most departments have procurement units with staff who have had procurement training. Heads of Departments are accountable

8. $\quad$ SFS 1998: 796 issued on 25 June 1998.

9. SI 1995/2011 (Public Supply Contracts Regulations) implements 93/36/EEC, the Supplies Directive. SI 1991/2680 (Public Works Contracts Regulations) implements 93/37/EEC, the Works Directive. SI 1993/3228 (Public Services Contracts Regulations) implements 92/50/EEC, the Services Directive. SI 1996/2911 (Utilities Contracts Regulations) implements 93/38/EEC, the Utilities Directive. The UK Procurement Policy Guidelines are available on the Treasury’s website: http://www.hm-treasury.gov.uk. 
to Parliament for the money voted to them to carry out their duties. The National Audit Office, which reports to Parliament and is independent of Government, scrutinises departmental expenditure firstly to verify that it is authorised and has been incurred for the purpose intended, and secondly, to examine whether value for money has been achieved.

Similar arrangements apply to other bodies for which departments are responsible, including the National Health Service. The NHS and local authorities are subject to audit by the Audit Commission, a statutory body that reports to Government Ministers and the public. There are similar arrangements in Scotland and Northern Ireland.

One feature of the decentralised approach is that the UK does not tie departments to using central buying agencies for their procurement, but these agencies should be used where they offer best value for money.

As a result of a review conducted in 1999 to look at whether the structure of procurement is suitable to meet future needs, for instance in taking full advantage of electronic commerce, a new body, the Office of Government Commerce was set up in 2000 to provide greater central co-ordination to the government's commercial activity. 